Rev, Chil. Pediatr. $68(1) ; 3-6,1997$

\title{
Dexametasona en meningitis bacteriana aguda del niño: Un análisis métrico
}

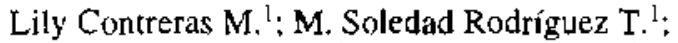 \\ Marcos Skarmeta M.'; Patricia Herrera L.'
}

\begin{abstract}
Resumen
Recieniemente se ha puesto en duda ta utilidac de la dexametasona en el mare c de la meningitis bacteriano aguda en riños, plantecndo un serio problemo de decisión elínica. Ya que el uso de caxametasona no sólo liene boses empíricos, se reviscron los espoldos bióógicos de su emploo, asi como ensoyos clínicos controlados en riños. Cinca es'udios cumplieron los criterios de intusión. Los resultodos respaldan el empieo de dexarretasonc en la

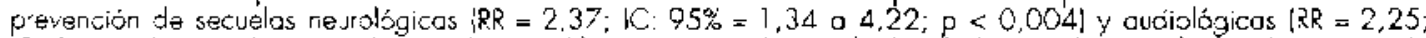
IC $95 \%=1,59$ a 3,2; $2<0,00003 \%$. Las diferencias eritre los resulados de los estud os pueden exolicarse por la Falic de comporabilidad (desiguoldaces en la duroción de la enfermedad anles del ciagnóstico, laalamientos y etiologial. Aunque los efecios de la dexametasona no son de la magnitud esoerada de los fundomentos biológicos. el esterside disminuye ios impacos globales neurológicos y audiologicos en los sobrevivientes y debería considerarse como teras a adjurito en meningitis bacieriana aguda, para emplearla con la desida cautela a los interrogantes sobre covariatles icles como la etiologío.
\end{abstract}

(Polabras elave: dexametosora, meningits.)

\section{Dexamethasone in acute bacterial meningitjs in children: a meta-analysis}

Recent p.bicaticns cost doub's about the usetulness of dexamethosone in the management of acute becterial meringitis in children, winich ra'ses serialss problems concernirig cinical decisions. Since the use of dexamethosone is not only based on emprical daro, we reviewec the biomedica intarmation winich suppots it, os well as clinicol studies in chitoren. Five sludies met inclussion citerio. Results favor dexarmethosone treame-1 to prevent reurological $1 R R=2.37$;

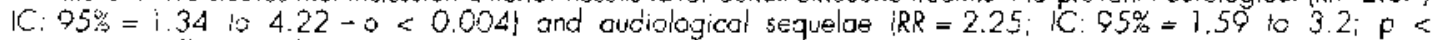
0.00003 ]. Diiferences found among study resuits noy be explained by nethocologica reassons like unequal periods of illress before diagnosis, trearrents and eliology. Although these effecrs are not os great as expected given the oiclagical rarionae fo: its use, dexamethasone does reduce overall neurological and audioiogical impack in children surviving from acule bacteria merirgitis and should be judiciously consicered as an adjunt heraoy. given uncertointies about some covarictes such as etiology

'Key words: dexame hosore, neningitis.'

Aunque la mortalidad por meningitis bacteriana aguda en niños ha experimentado una disminución significativa debido a los progresos en la terapia con antibiólicos y el apoyo de unidades de cuidado intensivo, la constatación de secuelas neurológicas en los sobrevivientes, espe-

J. Universidad de Chile. Facultad de Medicina, Departamento de Pediatría, Caimpus Norte. cialmente auditivas', ha acaparado el interés clínico en los últimos años. Desde el trabajo de $\mathrm{Odjo}^{2}$ el uso de dexametasona (DXM) ha sido aceptado como terapia complementaria de la meningitis bacteriana aguda, con el objeto de aminorar las secuelas en niños. Sin embargo, algunos estudios ${ }^{3.5}$ y opiniones recientes ${ }^{6}$ plantean dudas sobre la utilidad de esta terapia e inclusive sugieren eventuales inconvenientes? El ensayo de Odio ${ }^{2}$ responde en parte la hipóte- 
sis que propone que la DXM disminuye el riesgo de sccuelas en meningitis bacteriana aguda. Esta hipotesis se basa en extensos estudios experimentales analizados detalladamente en dos talleres de la Academia Americana de PediaIría ${ }^{\$ 9}$. El objelivo del siguiente análisis fue me. dir si el empleo de DXM tiene o no ventajas para disminuir las secuelas audiológicas y neurológicas en niños con meningitis bacteriana aguda, combinando los resultados de las experiencias soble su uso.

\section{Material y Métodos}

Se realizó una revisión de la bibliografía sobre las bases biológicas del uso de la DXM en meningitis bacteriana aguda y otra por Medline de los últimos 10 años, seleccionando ensayos clínicos controlados que compararon DXM con placebo como parte del tratamiento de la cnfermodad en niños. siguiendo las normas para la cjecución de metanálisis ${ }^{10}$. El criterio de inclusión requirió que los pacientes tueran niños de edad comparable de uno a otro estudio; se tratara de ensayos alcatorios y ciegos; se utilizara rerapia con DXM más cefalosporina de segunda o tercera generacion; los efectos atribuibles a la DXM cstuviesen estimados cuantitativamente como sccuelas audiologicas y neurológicas y se lubbese cumplido un seguimiento de por lo menos 6 meses. Los artículos fueron sometidos a un análisis clítico independiente a cargo de los cuatro autores, las diferencias de carácter metodológico fueron resueltas por criterio compartido. Cona vez identificados los artículos y los datos. éstos fueron sometidos a un análisis métrico con el objetivo de calcular el riesgo relativo resumen de Mantel Haenszel (RRMH), resultante de combinar los diferentes resultados expresados en $R R$, respecto a las probabilidades de secuclas audiológicas o neurológicas durante el seguimjentoll.

Se cmplearon proporciones como estadísticas descriptivas; riesgo relativo resumen de Mantel Hacnzsel como medida de asociación e intervato de cunfianza del $95 \%$ como expresión de dispersión. Como prueba de significación estadística se utilizó la de chi cuadrado, o la de Fisher cuando fue necesario. El nivel de significación esladistica elegido fue 0,025 .

\section{Resultados}

Se identificaron cinco estudios que cumplieron con los criterios de inclusión (tabla 1). En la figura aparecen las diferencias entre los porcentajes de secuelas observadas entre los grupos con placebo y DXM de los diversos estudios y muestra que alcanzaron nivel de significación estadística, en cuanto a secuela neurologica, sólo en los grupos estudiados por Odio ${ }^{2}$ y en relación a secuelas audiológicas, sólo en los de Lebel ${ }^{2}$.

En la tabla 2 aparecen los riesgos relativos de cada estudio y los RRMH correspondientes a la suma ponderada de los $R R$ de los distintos estudios, tanto para secuelas audiológicas como neurologicas. En ambos casos el RRMH es mayor que 1 y tiene un nivel de significación inferisor a 0,025 .

\section{Comentario}

De la revisión de las bases biológicas para el uso de la DXM en la meningitis bacteriana aguda ${ }^{8.9}$ se concluye que dicho esteroide actúa reduciendo el edema cerebral, la presión intracraneana, la respuesta inflamatoria, la resistencia a la reabsorción del LCR y la disrupción de la harrera hematoencefálica. Estos efectos se enlienden bajo el concepto de una acción precoz,

\section{Tabla 1}

Ensayos clínicos controlados incluidos en el análisis métrico

\begin{tabular}{lccl}
\hline Autor & Año & n de casos & Antibiótico \\
\hline Lebel s & 1988 & 51 & Cefuroximo \\
& & 49 & Placebo \\
Lebal 2 & 1988 & 51 & Ceftriaxona \\
& & 49 & Placebo \\
Odio & 1991 & 52 & Cefotaxima \\
& & 49 & Placebo \\
Schand & 1993 & 60 & Ceftriaxona \\
& & 55 & Placebo \\
Wald & 1994 & 69 & Ceftriaxona \\
& & 74 & Placebo \\
\hline
\end{tabular}


Tabla 2

Secuelas neurológicas:

\begin{tabular}{|c|c|c|c|c|c|c|c|c|c|c|}
\hline & \multicolumn{2}{|c|}{ Odio } & \multicolumn{2}{|c|}{ Wald } & \multicolumn{2}{|c|}{ Schaad } & \multicolumn{2}{|c|}{ Lebel 1} & \multicolumn{2}{|c|}{ Lebel 2} \\
\hline & Sí & No & Sî & No & Sí & No & Sí & No & Sí & No \\
\hline Placebo & 15 & 33 & 6 & 68 & 5 & 60 & 3 & 31 & 6 & 39 \\
\hline $\mathrm{DX}, \mathrm{W}$ & 5 & 46 & 4 & 64 & 3 & 57 & 1 & 37 & 2 & 41 \\
\hline Dif $\%$ & 21,4 & & 2.2 & & 4,1 & & 6.2 & & 8.7 & \\
\hline IC $95 \%$ & 5,6 & 37 & $-6,2$ & 11 & $-5,2$ & 13 & $-4,1$ & 17 & $-3,3$ & 21 \\
\hline $\mathrm{P}$ & 0,016 & & 0,854 & & 0,620 & & 0,53 & & 0.294 & \\
\hline RR & 3.19 & & 1,38 & & 1.82 & & 3,35 & & 2,87 & \\
\hline $\mathrm{IC} 95 \%$ & 1.2 & 8.1 & 0.4 & 4,7 & 0,46 & 7,3 & 0,37 & 30 & 0,6 & 13,4 \\
\hline
\end{tabular}

Secuelas audjológicas:

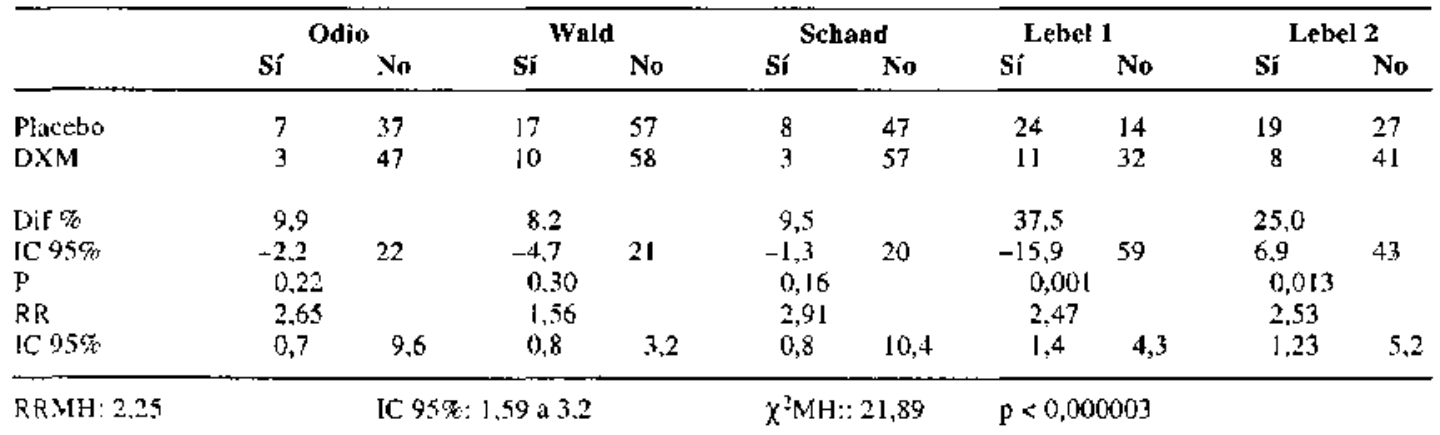

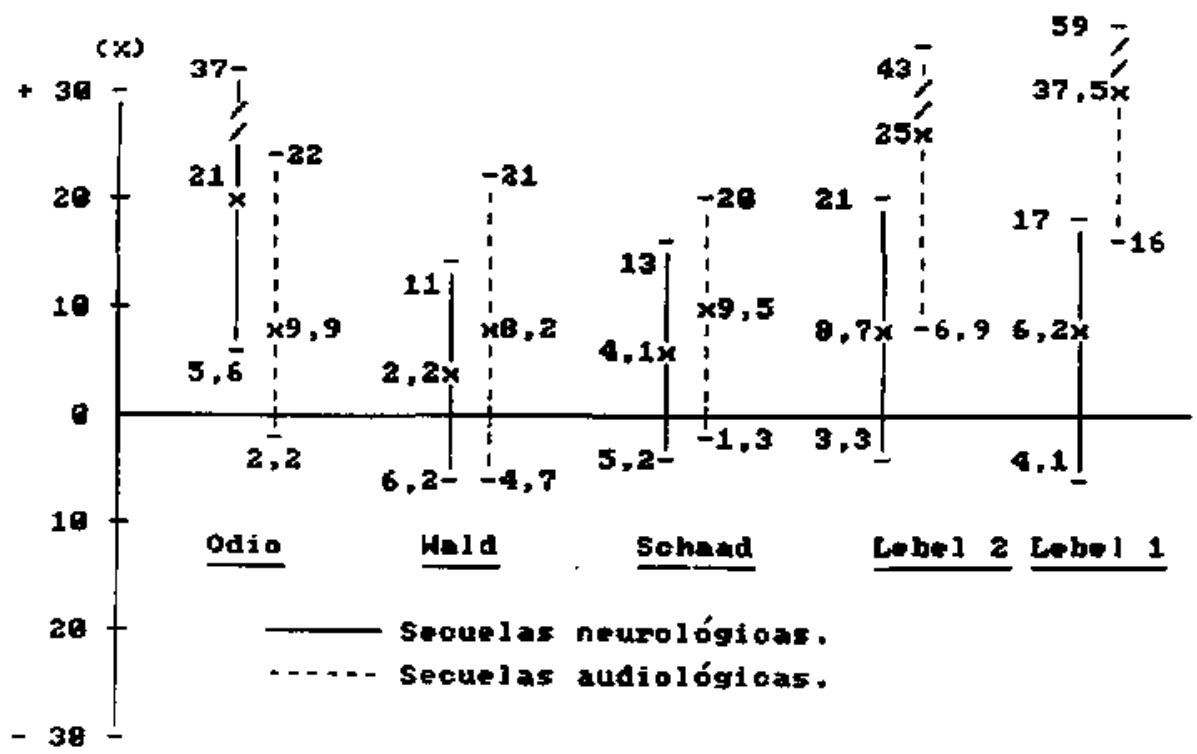

Figura: Diferencias entre grupos (placebo, DXM) y sus intervalos de confianza del $95 \%$, en cinco estudios de meningitis. 
preventiva, de la DXM, más bien que correctora de un proceso ya desencadenado. No hay, en tales estudios, elementos que sugieran que los mecanismos en que actúa la DXM dependan significativamente de la etiología. Del resultado de nuestro análisis puede deducirse que dicho esteroide es beneficioso para prevenir secuelas neurológicas y audiológicas cuando se usa en las fases iniciales del síndrome, aunque el grado de precocidad es imposible obtenerlo de los datos. Al examinar los intervalos de confianza de los RR de los distintos trabajos se puede apreciar que no hay argumentos suficientes para afirmar que difieren estadísticarnente; en cambio, su suma ponderada (RRMH) muestra que la DXM tienc efecto sobre las secuelas, pues las reduce en algo más de $50 \%$. Las divergencias entre los resultados de los distintos autores pueden deberse a diferencias entre las poblaciones, tamaños muestrales o del momento de la admiitistración de la DXM con respecto al inicio de la meningitis. Sin embargo, los datos analizados indican que la DXM es globalmente beneficiosa en estos niños como grupo, en términos de reducir el riesgo de secuelas, aunque es cierto que, dados nuestros resultados del análisis métrico. el beneficio parece modesto. El uso de DXM dehe estar sujeto al buen juicio clínico y considerar covariables no abordadas en los estudios, tales como la etiología -que ha sido propuesta como hipotéico factor de cambio de los efeclos de la DXM- y, obviamente, también factores como la edad, la oportunidad de su uso en el curso de la enfermedad, entre otros. La proposición de alrernativas al tratamiento con DXM debería suponer la reducción de más de $50 \%$ de sccuelas observadas con este esteroide.

Son limitaciones de este estudio la imposibilidad de acceder a trabajos no publicados sobre el tema y la de hacer análisis de sensibilidad debido a la forma de publicar los datos en los diferentes estudios analizados, lo que no dio lugar a eșla técnica.

\section{Referencias}

1. Herrera P: Análisis crítico de una revisión: demora en el tratamiento de la meningitis bacteriana aguda $y$ su significado. Pediatría (Santiagol 1993; 33: 16-24.

2. Odio CM. Fuingesich I, Paris $M$. et at: The beneficial effects of early dexamethasone administration in infants and children with bacterial meningitis. $N$ Engl J Med 1991: $324: 1525-1531$.

3. Lebet MH. Freij BJ. Syrogianfiopoulos GA. et at: Dexamethasone teraphy for bacterial meningitis: results of two double bind, placebo controlled trials. $\mathrm{N}$ Engl J Med 1988: 319: 964-971.

4. Wald E. Kaplum SL Mason EO, ef al: Dexamethasone therapy for children with bacterial meningits. Pediatrics 1995 ; $95: 21-28$.

5. Schad UB, Lips U, Gnehm HE, Blumberg A, Heinzes $I$, Wedgwood $J$ : Dexamethasone therapy for bacterial meningitis in childrer. Lancet 1993; 342:457-461.

6. Prober $C h G$. The role of steroids in the management of children with bacterial meningitis (Commentary). Pediatrics 1995: 95: 29-31.

7. Bradley JS: Dexamethasone therapy in meningitis potentially misleading antiinflamatory effects in cen. tral nervous system infections. Pediatr Infect Dis J 1994: 13: 823-826.

8. Sande MA. Scheld WM, MC Cracken GH Jr. and the Meningitis Study Group: Report of a workshop: pathophysiology of bacterial meningitis; implications for new management strategies. Pediatt lnfect Dis J 1987:6:1143-1171.

9. Sinde MA, Tüuber MG, Scheld $M$, MC Cracken GH atd the Meningirs Study Group: Report of a second workshop: pathophysiology of bacierial meningitis. Pediatr Infect Dis J 1989; 8: 899-933.

10. Laibé KA. Detsky AS, O'Rourke KO: El metaanálisis en la investigación clínica. Bol Of Sanit Panam 1994; I ] : 226-244.

11. Kleimbaun $D G$, Kupper $L L$, Morgenstern $H$ : Epidemiologic research $V$ an Nostrand Reinhold $C^{\circ}$ NY. 1982. 